\title{
Apresentação Típica de uma Variante Rara da Sarcoidose
}

\section{Typical Presentation of a Rare Variant for Sarcoidosis}

Maria Inês Bertão ${ }^{1 * *}$, Ana Sofia Costa ${ }^{1 *}$, Bárbara Baptista1 ${ }^{1}$ Sara Costa Fontainhas ${ }^{1}$, Maria do Rosário Santos Silva¹, Abílio Gonçalves ${ }^{1}$, Pedro Ramalho Rodrigues²

\section{RESUMO}

A síndrome de Löfgren é uma forma de apresentação aguda da sarcoidose que ocorre em até metade dos indivíduos com esta doença. O seu diagnóstico é mais frequente em mulheres caucasianas até aos 35 anos. Caracteriza-se pela tríade: eritema nodoso, linfadenopatias hilares bilaterais e poliartralgias.

A sarcoidose nodular trata-se de uma variante rara da sarcoidose cujo padrão, por mimetizar outras patologias, atrasa o diagnóstico de sarcoidose.

Descrevemos o caso de uma mulher caucasiana, de 30 anos, que recorreu ao Serviço de Urgência por edema dos membros inferiores e artralgias com seis dias de evolução. Analiticamente, apresentava elevação dos parâmetros inflamatórios, da velocidade de sedimentação e anemia. Radiografia torácica com alargamento dos hilos. A tomografia computorizada do tórax mostrou vários nódulos mediastínicos, hilares e pulmonares.

Apresentamos a marcha diagnóstica de uma variante rara de sarcoidose com uma apresentação clínica típica.

PALAVRAS-CHAVE: Artralgia; Artrite; Eritema Nodoso; Sarcoidose 


\section{ABSTRACT}

Löfgren's syndrome is a form of acute presentation of sarcoidosis that occurs in up to half of individuals with this disease. Its diagnosis is more frequent in Caucasian women up to 35 years old. It is characterized by the triad: knotty erythema, bilateral hilar lymphadenopathies and polyarthralgias.

Nodular sarcoidosis is a rare variant of sarcoidosis whose pattern, by mimicking other pathologies, delays the diagnosis of sarcoidosis.

We describe the case of a Caucasian woman, 30 years old, who went to the Emergency Department for edema of the lower limbs and arthralgias with six days of evolution. Analytically with increased inflammatory parameters, sedimentation speed and anemia. Chest radiography with enlargement of the hiluses. Computed tomography of the chest showed several mediastinal, hilar and pulmonary nodules.

We present the diagnostic march of a rare variant of sarcoidosis with a typical clinical presentation.

KEYWORDS: Arthralgia; Arthritis; Erythema Nodosum; Sarcoidosis

\section{INTRODUÇÃO}

A sarcoidose é uma doença inflamatória caracterizada pela formação de granulomas-não-caseosos em vários órgãos. ${ }^{1-6} \mathrm{O}$ órgão mais afetado é o pulmão. ${ }^{1,5} \mathrm{~A}$ etiologia da sarcoidose é desconhecida, mas assume-se que os fatores ambientais possam funcionar como triggers. ${ }^{1,2}$ É mais frequente em mulheres entre os 25 e 40 anos, e o segundo pico de prevalência da doença ocorre entre os 45 e 60 anos. ${ }^{1-3,7}$

A sarcoidose nodular é uma variante rara da sarcoidose presente em $2,4 \%$ a $4 \%$ dos casos, e é mais comum em afroamericanas. A presença de múltiplos nódulos pulmonares bilateralmente, periféricos, atrasa o diagnóstico desta variante rara, devido à necessidade de exclusão de patologias com apresentações idênticas. ${ }^{8}$

A síndrome de Löfgren ocorre em 20\% a 50\% dos doentes e caracteriza-se pela tríade: artralgias, eritema nodoso e adenopatias hilares bilaterais. A febre também é frequente. ${ }^{1,4,9}$ Esta entidade é autolimitada, apresenta bom prognóstico e há melhoria dos achados radiológicos após tratamento com corticoterapia. $2,3,9$

Descrevemos um caso incomum de sarcoidose nodular, com o objetivo de ilustrar a marcha diagnóstica e os diagnósticos diferenciais.

\section{CASO CLÍNICO}

Mulher de 30 anos, caucasiana, previamente saudável e sem antecedentes de relevo. Recorreu ao Serviço de Urgência (SU) por quadro de edema dos membros inferiores, febre e artralgias com seis dias de evolução. A doente negava consumo de tabaco, álcool ou drogas ilícitas.
Tinha história de dois abortamentos espontâneos e uma gravidez sem intercorrências. Como medicação habitual fazia apenas anticoncecional. Não tinha alergias medicamentosas conhecidas.

Ao exame objetivo, encontrava-se colaborante, vígil e orientada. Estava febril (temperatura auricular de $38,4^{\circ} \mathrm{C}$ ), eupneica em ar ambiente, normotensa (110/65 mmHg) e normocárdica (70 batimentos por minuto). Não tinha alterações à auscultação cardíaca ou pulmonar. Abdómen mole e depressível, indolor, sem organomegalias. Apresentava edema e exantema nodular doloroso exuberante nos membros inferiores, na região anterior pré-tibial e tibiotársica. Apresentava artrite das tibiotársicas bilateralmente, sem outras articulações afetadas (Fig. 1). Sem adenopatias supraclaviculares, cervicais, inguinais ou axilares palpáveis.

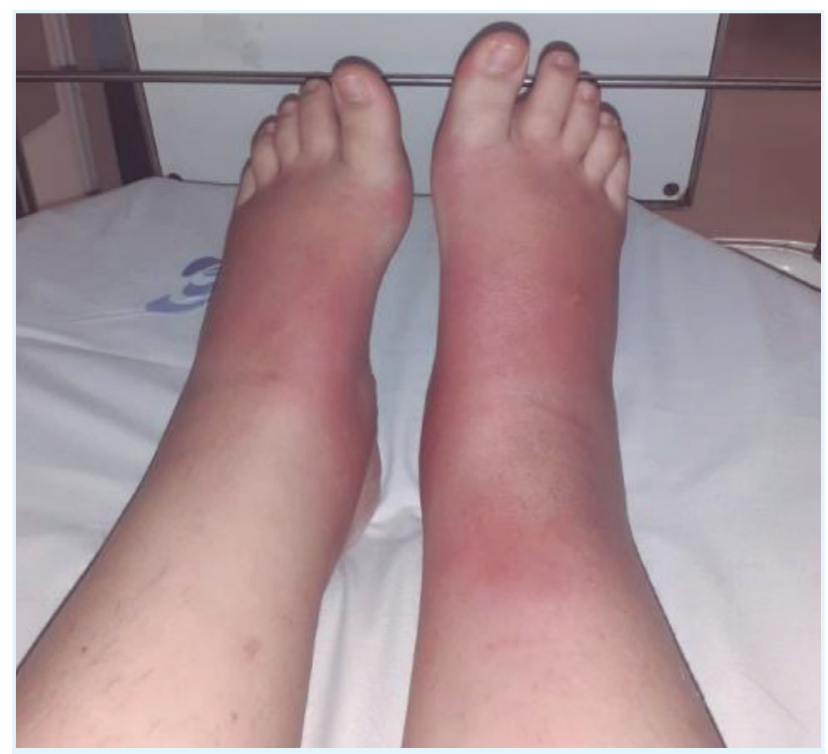

FIGURA 1. Edema dos membros inferiores e eritema nodoso associado a edema das tibiotársicas. 
Analiticamente, apresentava uma ligeira neutrofilia de $7,52 \times 10^{3} / \mu \mathrm{L}$ (76,4\%), anemia normocítica normocrómica (Hb de 11,7 g/dL), VS de 65 mm/1h e PCR de 171 mg/L, com função renal e hepática dentro da normalidade.

Atendendo às hipóteses diagnósticas, foi proposto internamento para estudo. Durante o internamento fez estudo complementar: Fator reumatoide ligeiramente aumentado (24 para um limite superior do normal de 14). Anticorpos antinucleares (ANA), anticorpos anti-dsDNA, anticorpo anticitoplasmático de neutrófilo (ANCA) e anticorpo Saccharomyces cerevisiae (ASCA) negativos. Estudo da síndrome anticorpo antifosfolipídico foi negativo. Interferon-gama da micobactéria (IGRA) negativo. Doseamento da enzima de conversão da angiotensina (SACE) normal. Peptídeos citrolinados cíclicos negativos. Antigénios urinários negativos para pneumococo e Legionella. Pesquisa por zaragatoa da síndrome respiratória aguda grave de coronavírus-2 (SARS-CoV-2) negativa. Hemoculturas e uroculturas estéreis. Serologias negativas para o vírus da imunodeficiência humana $(\mathrm{VIH})$, vírus da hepatite $\mathrm{C}(\mathrm{VHC})$ e vírus da hepatite B (VHB). Beta-2 microglobulina ( $\beta 2$ microglobulina) elevada (2230 $\mu \mathrm{g} / \mathrm{L})$.

Realizou telerradiografia do tórax que revelou alargamento dos hilos bilateralmente (Fig. 2).

A tomografia computorizada (TC) do tórax revelou adenopatias mediastínicas e hilares (pré-vasculares, para-traqueais, subcarinais, hilares direitas e hilares esquerdas), nódulo pulmonar cisural com 6 mm no segmento anterior do lobo inferior direito e espessamento dos septos interlobulares nos lobos inferiores (Fig. 3).

A biópsia de uma das lesões cutâneas apresentava dermahipodermite septal entre granulomas de Miescher.

Teve alta com naproxeno 500 mg 2 vezes ao dia para o eritema nodoso enquanto se fazia o estudo da etiologia do quadro.

Durante o seguimento, desenvolveu astenia, dispneia para médios esforços, agravamento das dores articulares e queixas de mialgias e parestesias nos membros inferiores bilateralmente. Analiticamente, observada creatinofosfoquinase (CPK) normal e elevação da SACE até ao valor máximo de $66 \mathrm{U} / \mathrm{L}$. Por manter nódulos cutâneos, iniciou colchicina com boa resposta clínica.

Foi realizada TC tórax de reavaliação, três semanas depois, que evidenciou um agravamento das alterações pulmonares com micronódulos e aparecimento de múltiplos nódulos dispersos em ambos os campos pulmonares de predomínio subpleural e peri-brônquico (Fig. 4).

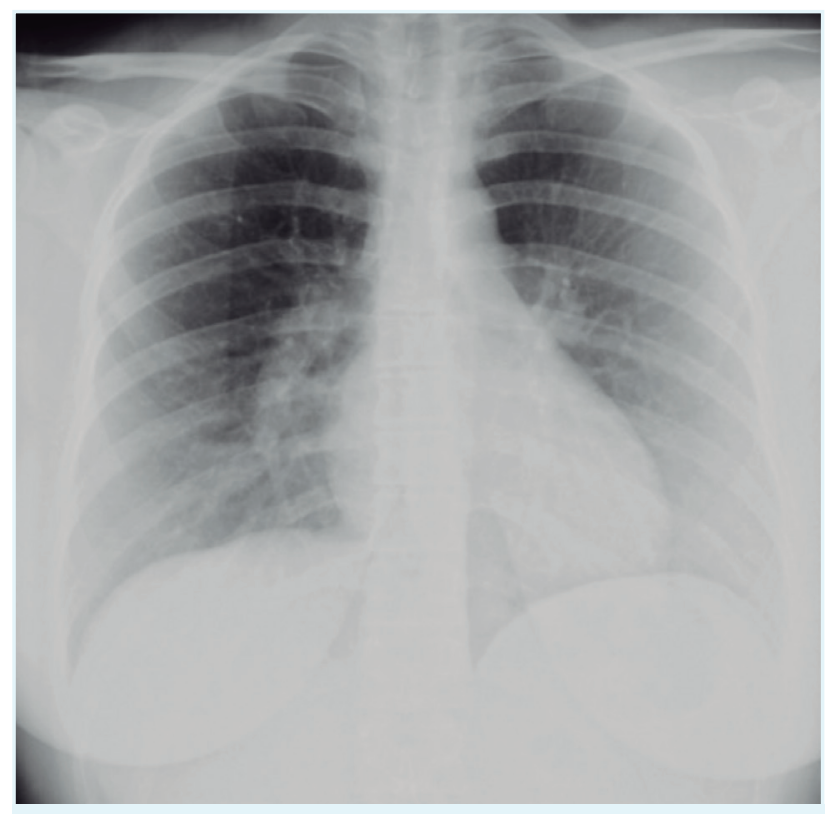

FIGURA 2. Radiografia do tórax à admissão com alargamento dos hilos bilateralmente.

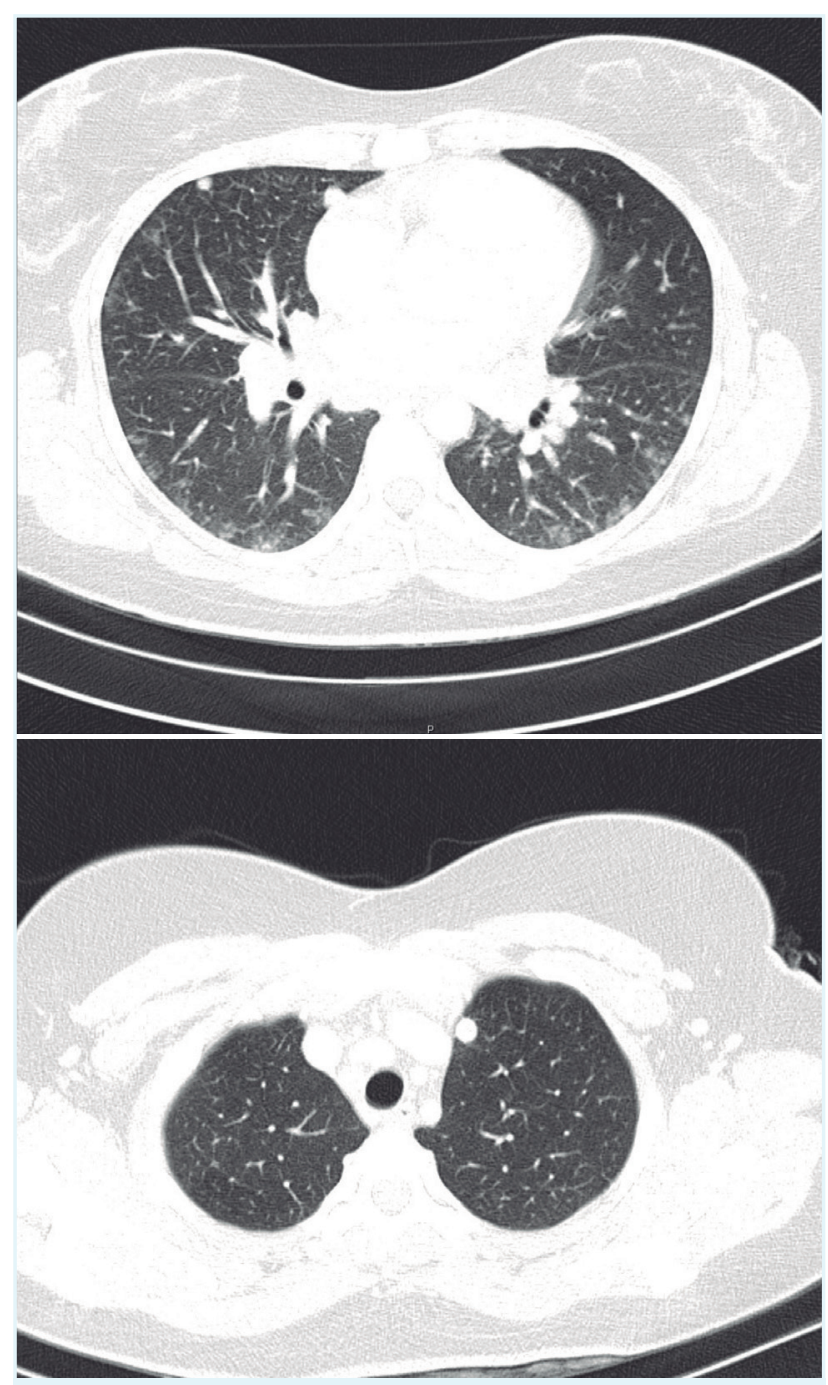

FIGURA 3. Adenopatias mediastínicas e hilares (pré-vasculares, para-traqueais, subcarinais, hilares direitas e hilares esquerdas), nódulo pulmonar cisural com 6 mm no segmento anterior do lobo inferior direito e espessamento dos septos interlobulares nos lobos inferiores. 


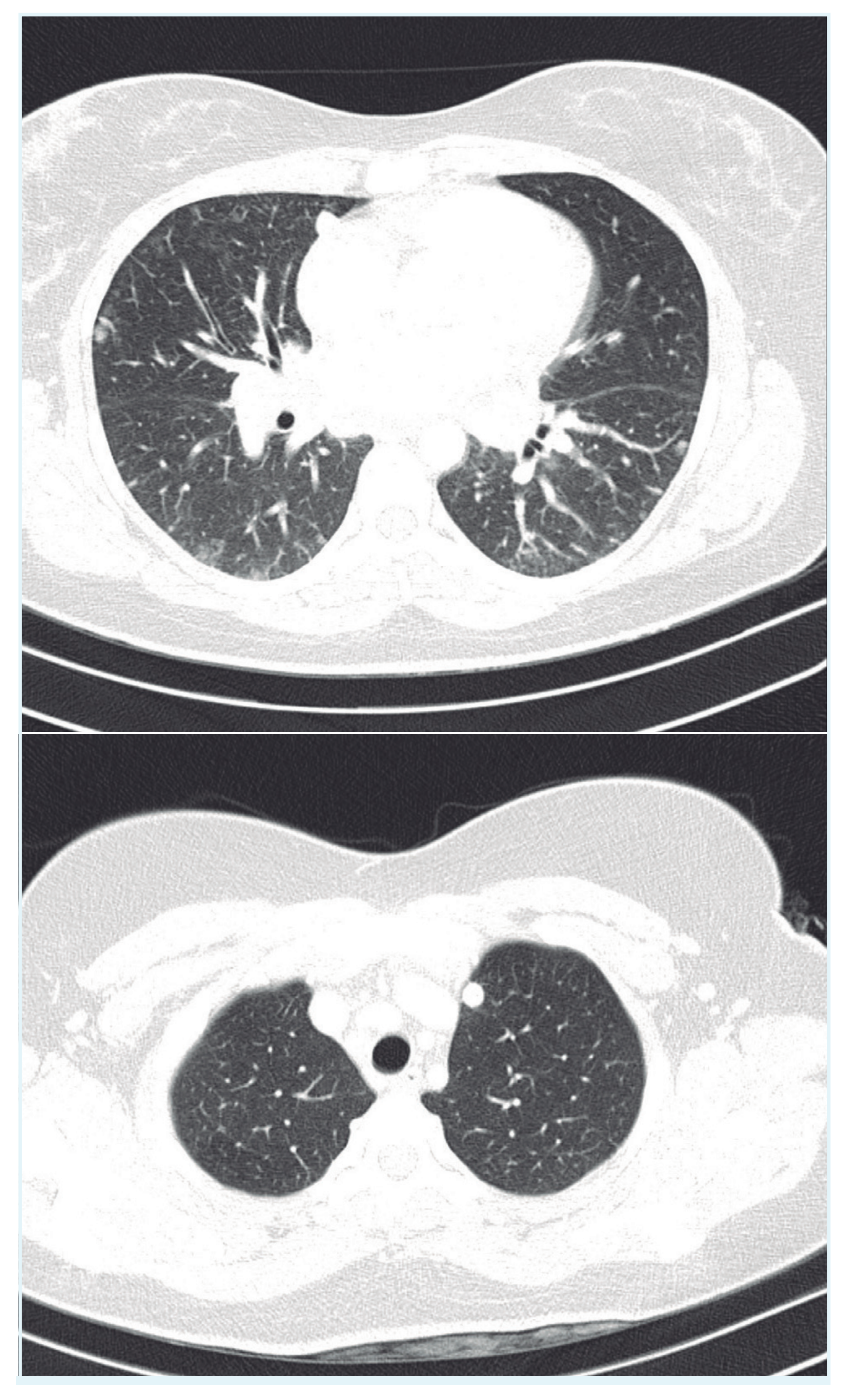

FIGURA 4. TC tórax de reavaliação 3 semanas depois revelando o complexo mediastino com várias adenopatias. Na janela do pulmão padrão de micronodulação e espessamento dos septos.

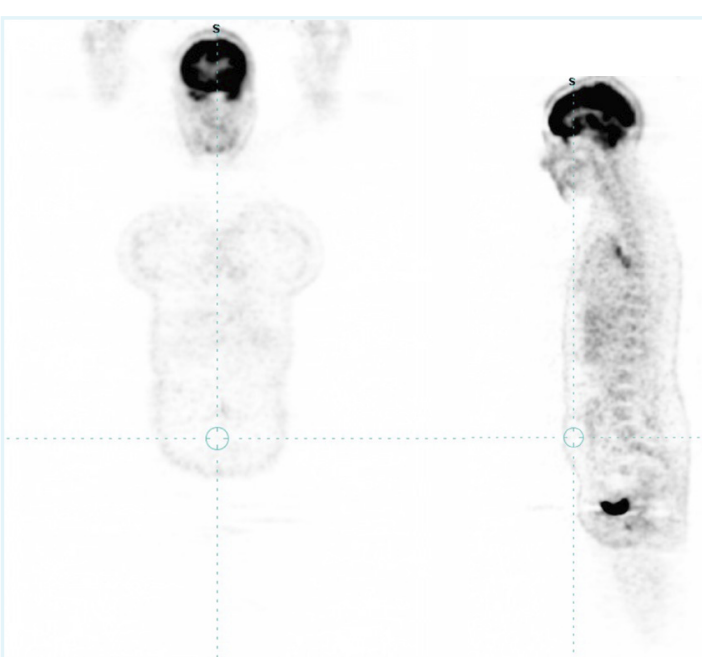

FIGURA 5. PET - Padrão nodular de natureza inflamatória em fase moderada de atividade.
Foi realizada broncofibroscopia com lavado brônquico que apresentou aspetos inflamatórios ligeiros, sem critérios de especificidade, não tendo sido possível colher material para fenotipagem dos linfócitos CD4 e CD8. Fez provas funcionais respiratórias que revelaram diminuição ligeira da capacidade de difusão alvéolo-capilar. Realizou ecografia endobrônquica (EBUS) que foi inconclusiva por não se obter material ganglionar alterado. A eletromiografia não revelou sinais de lesão de fibra muscular ao nível dos músculos estudados nos membros inferiores e superiores.

Foi realizada tomografia com emissão de positrões (PET) que revelou disperso pelo parênquima de ambos os pulmões um padrão de micronodulação, em sede preferencialmente subpleural associado a espessamentos pleurais bilateralmente, a densificação mais evidente no segmento apical do lobo superior direito e à esquerda do segmento apical do lobo superior. Identificaram-se múltiplas adenopatias hipermetabólicas latero-cervicais, mediastino-hilares bilaterais e abdominais em relação com alterações de natureza inflamatória em fase moderada de atividade (Fig. 5).

Assumido o diagnóstico de sarcoidose nodular, iniciou terapêutica com prednisolona 60 mg uma vez por dia, com boa resposta clínica e imagiológica. Porém, por desenvolver efeitos adversos da corticoterapia, optou-se por associar a azatioprina à terapêutica com prednisoIona. Atualmente, 6 meses depois de ter iniciado o tratamento, mantém-se sob desmame de corticoterapia sistémica, em vigilância da evolução clínica em consulta de medicina interna e de pneumologia. A TC-tóracica de reavaliação aos 6 meses demonstra desaparecimento dos nódulos e adenopatias e com resolução completa do quadro (Fig. 6).

\section{DISCUSSÃO}

A sarcoidose representa um desafio diagnóstico, principalmente devido às hipóteses de diagnóstico com características clínicas semelhantes, nomeadamente tuberculose, infeções bacterianas atípicas, infeções fúngicas, pneumonite de hipersensibilidade, pneumoconiose, hipersensibilidade induzida por fármacos, histiocitose de células de Langerhans, vasculite, granulomatose broncocêntrica, imunodeficiência primária, neoplasia sarcoidose-like, linfoma.

A sarcoidose nodular é reconhecida pela aparência típica semelhante a uma "bola de neve". Os nódulos tipicamente resultam da coalescência de granulomas, têm uma apresentação semelhante aos metastáticos atingindo até $5 \mathrm{~cm}$ de maior diâmetro. $\bigcirc$ curso clínico é benigno e é comum ser auto-limitada. ${ }^{8}$ 


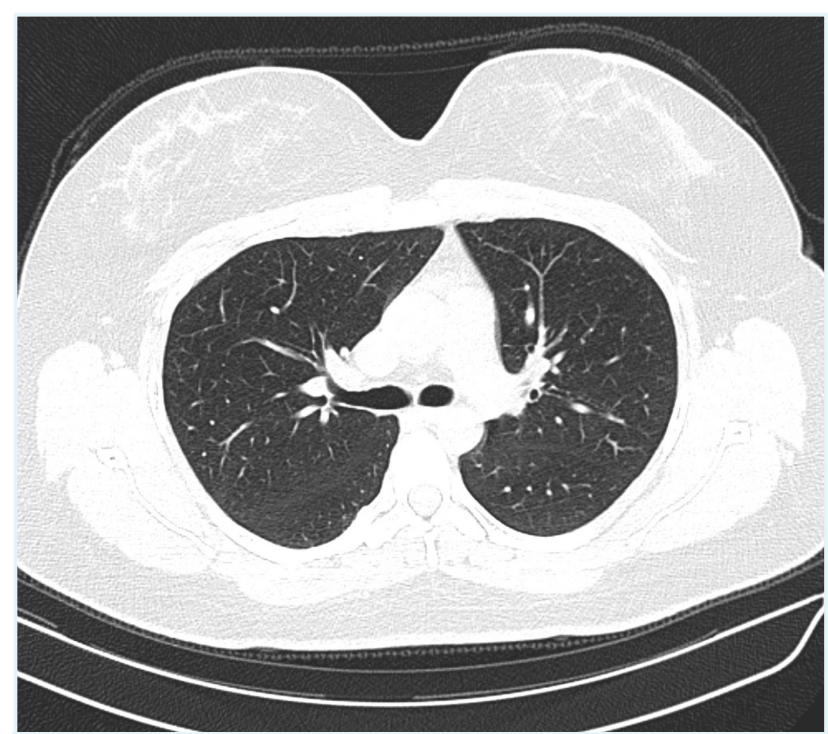

FIGURA 6. TC após 6 meses de tratamento com corticoides.

Descrevemos um caso típico de síndrome de Löfgren, com clínica sugestiva e tradução imagiológica na telerradiografia do tórax. Quando esta síndrome se apresenta, a especificidade diagnóstica é superior a 95\%, ${ }^{2}$ no entanto, apesar do elevado valor preditivo positivo da clínica, ${ }^{3,10}$ perante a evidência de um quadro constitucional com dispneia e nódulos pulmonares, iniciamos a marcha diagnóstica com exclusão das principais hipóteses diagnósticas descritas. ${ }^{11,12}$

A pesquisa de BK no lavado broncoalveolar e o IGRA foram negativos, o que excluiu tuberculose. Foi também excluída a hipótese de se tratar de uma vasculite, pois a doente tinha ANA e ANCA negativos e eletromiografia sem alterações.

A enzima de conversão da angiotensina apresenta-se elevada em mais de metade dos doentes com sarcoidose na sua forma aguda., ${ }^{2,10}$ Quando os níveis aumentam mais do dobro do limite superior do normal, diminui a probabilidade de doenças neoplásicas. Na síndrome de Löfgren esta elevação é significativamente mais baixa podendo mesmo ser normal. ${ }^{4}$ No caso clínico apresentado, verificou-se uma elevação discreta durante o seguimento. No entanto, este doseamento é pouco específico e pouco sensível, não sendo útil como teste de screening. ${ }^{2}$

De acordo com a literatura, a proteína $\mathrm{C}$ reativa (PCR) apresenta-se elevada na síndrome de Löfgren, o que sugere o eventual efeito protetor deste marcador. ${ }^{4} \AA$ admissão, a doente tinha uma PCR elevada (valor de 171 para um limite superior do normal de $5 \mathrm{mg} / \mathrm{L}$ ), que normalizou após instituição da terapêutica.

Embora frequentemente associados a um padrão restritivo, verifica-se que os doentes que se apresentam com a síndrome de Löfgren têm uma avaliação da função respiratória idêntica a indivíduos saudáveis. ${ }^{4,8}$

Foi realizada uma PET pelo seu elevado valor preditivo positivo no diagnóstico de neoplasia. No caso descrito, confirmou-se um padrão nodular de sarcoidose.

O tratamento da sarcoidose depende da gravidade, manifestações e órgãos afetados. Se o doente apresentar apenas manifestações cutâneas estão indicados, entre outros, corticoides tópicos e tacrolimus. Se o envolvimento for sistémico, recomendam-se terapêuticas imunomoduladoras (cloroquina/ hidroxicloroquina) e imunossupressoras (prednisolona, metotrexato, azatioprina e micofenolato de mofetil). Caso se trate de uma sarcoidose pulmonar ou extrapulmonar refratária, adalimumab ou infliximab também podem ser usados. Em doentes com síndrome de Löfgren, a colchicina tem apresentado bons resultados no tratamento do eritema nodoso. ${ }^{2}$ Foi escolhida a azatioprina em detrimento do metotrexato pelo atingimento preferencialmente pulmonar neste caso.

A maioria dos casos de síndrome de Löfgren é conservador e resolve com repouso e anti-inflamatórios não esteroides, mas em alguns casos, como o caso apresentado, é necessária prednisolona numa dose de $1 \mathrm{mg} /$ kg.,10 Ao contrário da sarcoidose que exige terapêutica durante longos períodos, esta síndrome apresenta um bom prognóstico com remissão ao fim de 1 ano.,310

\section{CONCLUSÃO}

A apresentação clínica apesar de compatível com a tríade clínica típica da síndrome de Löfgren, a presença de achados imagiológicos suspeitos de malignidade impôs um raciocínio clínico exigente pela marcha diagnóstica e diagnósticos diferenciais envolvidos.

Os autores pretendem realçar um caso interessante de diagnóstico de sarcoidose nodular, no qual foi difícil obter material ganglionar alterado. Contudo, perante as imagens altamente sugestivas e o quadro de apresentação típica, foi instituída terapêutica. Após 6 meses de corticoterapia, a melhoria clínica e imagiológica foram evidentes o que confirma a suspeita diagnóstica de sarcoidose nodular.

\section{AGRADECIMENTOS}

Pedro Ramalho Rodrigues, Assistente Hospitalar de Pneumologia, Serviço de Pneumologia do Hospital Distrital da Figueira da Foz. 


\section{RESPONSABILIDADES ÉTICAS}

CONFLITOS DE INTERESSE: Os autores declaram a inexistência de conflitos de interesse na realização do presente trabalho.

FONTES DE FINANCIAMENTO: Não existiram fontes externas de financiamento para a realização deste artigo.

CONFIDENCIALIDADE DOS DADOS: Os autores declaram ter seguido os protocolos da sua instituição acerca da publicação dos dados de doentes.

CONSENTIMENTO: Consentimento do doente para publicação obtido.

PROVENIÊNCIA E REVISÃO POR PARES: Não comissionado; revisão externa por pares.

\section{ETHICAL DISCLOSURES}

CONFLICTS OF INTEREST: The authors have no conflicts of interest to declare.

FINANCING SUPPORT: This work has not received any contribution, grant or scholarship.

CONFIDENTIALITY OF DATA: The authors declare that they have followed the protocols of their work center on the publication of data from patients.

PATIENT CONSENT: Consent for publication was obtained.

PROVENANCE AND PEER REVIEW: Not commissioned; externally peer reviewed.

\section{REFERÊNCIAS}

1. Kasper DL, Fauci AS, Hauser SL, Longo DL, Jameson JL, Loscalzo J. Harrison's principles of internal medicine. 20th ed. New York: McGraw Hill Education; 2018.

2. Montoya-Castillo M, Herrera-Uribe S, Berlinghieri-Pérez JD. Löfgren syndrome as an acute presentation of sarcoidoisis. Rev Colombiana Reumatol. 2018;25:126-31. doi:10.1016/j. rcreu.2017.04.005.

3. Klevtsova E, Madruga M, Carlan SJ, Wilson J. Löfgren syndrome misdiagnosed as lower-extremity cellulitis. J Clin Rheumatol. 2015;21:271-2. doi: 10.1097/RHU.0000000000000275.

4. Ambrósio C, Malcata A. Síndrome de Löfgren: a importância da radiografia torácica Acta Reumatol Port. 2009;34:426-30.

5. Ohta H, Tazawa R, Nakamura A, Kimura Y, Maemondo M, Kikuchi T, Ebina M, Nukiwa T. Acute-onset sarcoidosis with erythema nodosum and polyarthralgia (Löfgren's syndrome) in Japan: a case report and a review of the literature. Intern Med. 2006;45:659-62. doi: 10.2169/internalmedicine.45.1452.

6. Kobak S. Sarcoidosis: a rheumatologist's perspective. Ther Adv Musculoskelet Dis. 2015;7:196-205. doi: 10.1177/1759720X15591310.

7. Karakaya B, Kaiser Y, van Moorsel CHM, Grunewald J. Löfgren's Syndrome: Diagnosis, Management, and Disease Pathogenesis. Semin Respir Crit Care Med. 2017;38:463-76. doi: 10.1055/s-0037-1602380.
8. McCullough PC, McCullough AE. Images in clinical medicine. Nodular sarcoidosis. N Engl J Med. 2002;346:1970. doi: 10.1056/NEJMicm990757.

9. Cheng DR, Maini A. Löfgren's syndrome misdiagnosed as celIulitis. Emerg Med Australas. 2011;23:376-8. doi: 10.1111/j. 1742-6723.2011.01426.x.

10. Costa J, Lucas C, Paixão J, Rodrigues A. Síndrome Löfgren - o melhor cenário da sarcoidose. Rev Ciencias Salud. 2019;17:149-55. doi: 10.12804/revistas.urosario.edu.co/revsalud/a.7624.

11. Sweidan AJ, Singh NK, Stein A, Tanios M. Nodular Sarcoidosis Masquerading as Cancer. Clin Med Insights Circ Respir Pulm Med. 2017;11:1179548417703123. doi: 10.1177/1179548417703123.

12. Shahzad H, Ur-Rehman S, Fatima K, Sharif N, Zubairi AB. Case series and literature review of multiple nodular sarcoidosis. BMC Res Notes. 2013;6:394. doi: 10.1186/1756-0500-6394. 